(c) <2021 > . This manuscript version is made available under the CC-BY-NC-ND 4.0 license http://creativecommons.org/licenses/by-nc-nd/4.0/

The definitive publisher version is available online at https://doi.org/ 10.1016/..nanoen.2021.105839 


\section{Nano-synergy enables highly reversible storage of 9.2 wt\% hydrogen at mild conditions with lithium borohydride}

Xin Zhang, ${ }^{a}$ Lingchao Zhang, ${ }^{a}$ Wenxuan Zhang, ${ }^{a}$ Zhuanghe Ren, ${ }^{a}$ Zhenguo Huang, Jianjiang Hu, ${ }^{\mathrm{c}}$ Mingxia Gao, ${ }^{\mathrm{a}}$ Hongge Pan, ${ }^{\mathrm{a}}$ Yongfeng Liu ${ }^{\mathrm{a}, *}$

aState Key Laboratory of Silicon Materials and School of Materials Science and Engineering, Zhejiang University, Hangzhou 310027, China

${ }^{\mathrm{b} S c h o o l}$ of Civil \& Environmental Engineering, University of Technology Sydney, 81 Broadway, Ultimo, NSW, 2007, Australia

'School of Chemistry and Chemical Engineering, Yantai University, Yantai 264005, China

*Corresponding Author

E-mail: mselyf@zju.edu.cn 


\section{ABSTRACT:}

In this work, we report an effective synthetic strategy to obtain $\mathrm{LiBH}_{4}$ featuring lowtemperature and highly reversible hydrogen cycling. This is achieved by a unique nanocomposite structure where $\mathrm{LiBH}_{4}$ nanoparticles of 5-10 nm on graphene are decorated by $\mathrm{Ni}$ nanocrystals of $2-4 \mathrm{~nm}$. The prepared $\mathrm{LiBH}_{4}$ nanocomposite reversibly desorbs and absorbs $\sim 9.2 \mathrm{wt} \%$ hydrogen at $300{ }^{\circ} \mathrm{C}$ with a stable cyclability for up to 100 cycles, superior to all the literature results reported so far. The decisive factor affecting the hydrogen cycling is the reactivity of boron toward hydrogen. The formation of stable $\mathrm{B}_{12} \mathrm{H}_{12}{ }^{2-}$ cluster during hydrogen cycling has been successfully prevented. The synergetic effects of nanostructuring and nanocatalysis lead to efficient formation of $\mathrm{BH}_{4}^{-}$during hydrogenation and elemental boron during dehydrogenation. This breakthrough sheds light on new strategies to explore borohydride family for practical hydrogen storage applications.

Keywords: hydrogen storage; complex hydride; lithium borohydride; nanoparticles; nanocatalysis 


\section{Introduction}

For hydrogen storage materials, hydrogen cycling, i.e., dehydrogenation and hydrogenation, under mild conditions is a prerequisite for practical applications [1,2]. Metal borohydrides $\left(\mathrm{M}\left(\mathrm{BH}_{4}\right)_{x}\right)$ have been most widely studied for hydrogen cycling due to their high hydrogen capacities [3-5]. In general, hydrogen can be released from $\mathrm{M}\left(\mathrm{BH}_{4}\right)_{x}$ through two methods, viz., hydrolysis and thermolysis [6,7]. For hydrogen cycling, the low-cost and high-yield regeneration of the spent borohydrides is the key issue in the hydrolysis mode [8-10], while the thermolysis typically requires high pressure and/or high temperature, which results in reduced net energy output [11-13]. For example, $\mathrm{LiBH}_{4}$ has been regarded as one of the most promising hydrogen storage media due to its high gravimetric $(18.5 \mathrm{wt} \%)$ and volumetric $\left(121 \mathrm{~kg} \mathrm{~m}^{-3}\right)$ hydrogen densities. However, over $400{ }^{\circ} \mathrm{C}$ is usually needed for dehydrogenation and $>350$ bar $\mathrm{H}_{2}$ is required for rehydrogenation [7]. In general, borohydrides suffer from two problems due to the unique boron chemistry. One is the formation of diborane gas $\left(\mathrm{B}_{2} \mathrm{H}_{6}\right)$ during dehydrogenation, whose evolution means a loss of boron and consequently poor recyclability [14]. The other is the formation of $\mathrm{Li}_{2} \mathrm{~B}_{12} \mathrm{H}_{12}$ intermediate which has high thermal stability and acts as a 'boron sink' preventing the re-formation of $\mathrm{LiBH}_{4}$ [15]. It is therefore critical to 1) keep the boron in the system by suppressing the formation of $\mathrm{B}_{2} \mathrm{H}_{6}$, and 2) maintain the reactivity of boron by avoiding the formation of $\mathrm{B}_{12} \mathrm{H}_{12}{ }^{2-}$.

Various strategies have been explored to improve hydrogen storage properties of metal borohydrides, such as anion/cation mixing, introducing catalysts, fabricating reactive composites, and nanostructuring [16-21]. Considerable amounts of research has proven that nanostructured metal borohydrides offer faster desorption rates and lower desorption temperatures compared to their bulk counterparts, thanks to the 
increased specific surface area, abundant grain boundaries/defects and shortened mass transport path $[22,23]$. The $20-50 \mathrm{~nm}$-sized $\mathrm{LiBH}_{4}$ prepared by a solvent evaporation process started releasing $\mathrm{H}_{2}$ even from $\sim 32{ }^{\circ} \mathrm{C}$ and about $3.5 \mathrm{wt} \% \mathrm{H}$ was released when heating to $265{ }^{\circ} \mathrm{C}$, which is nearly 5 -fold higher than that released from bulk $\mathrm{LiBH}_{4}$ [24]. More importantly, nanostructuring can effectively suppress the formation of $\mathrm{B}_{2} \mathrm{H}_{6}$, which favors the reversibility [25]. Recently, nanoconfinement was widely used to prepare particles smaller than $20 \mathrm{~nm}$ by depositing hydrides on a support or infiltrating into nanoporous scaffold such as carbon materials, ordered mesoporous oxides, zeolites, and metal-organic frameworks [26-31]. Combining nanoconfinement and nano Ni catalyst further enhanced the overall performance under mild conditions $[32,33]$. Unfortunately, the support compromises the practical gravimetric hydrogen capacity of the system because of low loading of $\mathrm{LiBH}_{4}$ (50\% or less) [26-31]. Lowweight graphene with large surface area proves effective in encapsulating hydrides, enabling high loading of nanomaterials and superior catalytic activity [22]. Xia et al. prepared 2-nm thick $\mathrm{LiBH}_{4}$-decorated graphene sheets $\left(\mathrm{LiBH}_{4} @ \mathrm{G}\right)$ with a loading as high as $69.1 \mathrm{wt} \%$, and the dehydrogenation peak temperature was reduced by $124{ }^{\circ} \mathrm{C}$ to $346{ }^{\circ} \mathrm{C}$ [34]. However, the preparation involved multiple steps and employed highly toxic and flammable $\mathrm{B}_{2} \mathrm{H}_{6}$, and hydrogen capacity rapidly faded from $9.4 \mathrm{wt} \%$ to $7.5 \mathrm{wt} \%$ in only 5 cycles, possibly due to the formation of $\mathrm{Li}_{2} \mathrm{~B}_{12} \mathrm{H}_{12}$. The presence of $\mathrm{Li}_{2} \mathrm{~B}_{12} \mathrm{H}_{12}$ has also been observed in various nanocomposites, which is believed to be the key factor for the poor hydrogen cycling [35-37]. Previous reports have demonstrated that nano $\mathrm{Ni}$ could work as an effective catalyst to facilitate the regeneration of $\mathrm{BH}_{4}^{-}$by retarding the formation of $\mathrm{B}_{12} \mathrm{H}_{12}{ }^{2-}[32,33]$. So far, it has been challenging to simultaneously achieve high hydrogen capacity, low operating temperatures, and good reversibility. 
In this work, we demonstrate success in achieving high hydrogen cycling stability and high capacity at remarkably low temperatures at the same time. The key innovation lies in keeping the boron active in the system by nanostructuring and nanocatalysis. A unique nanocomposite consisting of Ni nanocrystal-decorated $\mathrm{LiBH}_{4}$ nanoparticles of $<10 \mathrm{~nm}$ anchored on graphene was fabricated by a facile one-pot solvothermal synthesis. The catalysis by nanosized $\mathrm{Ni}$ and support by graphene play key roles in suppressing the formation of $\mathrm{B}_{2} \mathrm{H}_{6}$ and $\mathrm{B}_{12} \mathrm{H}_{12}{ }^{2-}$ and thus contribute to the outstanding hydrogen cycling performance. Our strategy is of general applicability for the preparation of catalyst-decorated nanostructured metal borohydrides, which brings an important step towards practical utilization of borohydrides as high-capacity hydrogen carriers.

\section{Methods}

\subsection{Materials synthesis}

Commercial chemicals including n-butyl lithium $\left(\mathrm{C}_{4} \mathrm{H}_{9} \mathrm{Li}, \mathrm{n}-\mathrm{BuLi}, 2.0 \mathrm{M}\right.$ in cyclohexane, Sigma-Aldrich), $\left(\mathrm{C}_{2} \mathrm{H}_{5}\right)_{3} \mathrm{NBH}_{3}\left(97 \%\right.$, Aladdin), nickelocene $\left(\mathrm{C}_{10} \mathrm{H}_{10} \mathrm{Ni}\right.$, $\mathrm{Cp}_{2} \mathrm{Ni}, 98 \%$, Aladdin), n-hexane (97.5\%, SuperDry, Acros Organics) and graphene (>95\%, Aladdin) were purchased and used as received. The Ni nanocrystal-decorated $\mathrm{LiBH}_{4}$ nanoparticles anchored on graphene were synthesized by a one-pot solvothermal strategy. In a typical procedure, $2 \mathrm{~mL} \mathrm{C}_{4} \mathrm{H}_{9} \mathrm{Li}$ solution $(2 \mathrm{M}$ in cyclohexane), $460 \mathrm{mg} \mathrm{C}_{6} \mathrm{H}_{18} \mathrm{BN}, 48 \mathrm{mg} \mathrm{Cp}{ }_{2} \mathrm{Ni}$ and $22 \mathrm{mg}$ graphene were first dispersed in $80 \mathrm{~mL}$-hexane with sonication for $2 \mathrm{~h}$. The mixture solution was then transferred into a custom-designed stainless steel autoclave with a volume of $150 \mathrm{~mL}$. The autoclave was then filled with 50 bar $\mathrm{H}_{2}$ and the solvothermal reaction was conducted at $100{ }^{\circ} \mathrm{C}$ for $24 \mathrm{~h}$ with a constant-rate stirring. Subsequently, the solid 
product was centrifuged and ultrasonically washed twice with n-hexane to remove byproducts. Finally, the resultant powders were dried at $90{ }^{\circ} \mathrm{C}$ through dynamic vacuum to remove triethylamine.

\subsection{Materials characterization}

The phase structure was characterized using an X'Pert Pro X-ray diffractometer (XRD, Rigaku, Japan) with $\mathrm{Cu} \mathrm{K} \alpha$ radiation $(\lambda=0.15406 \mathrm{~nm}, 40 \mathrm{kV}$ and $15 \mathrm{~mA})$. The XRD data were collected in the $2 \theta$ range of $10-90^{\circ}$ with $0.05^{\circ}$ step increments at room temperature. The sample was sealed in a custom-designed holder with a window covered by Scotch tape for transmission of X-ray but impermeable to air and moisture. FTIR analysis was employed to identify the B-H vibrations by using a Bruker Tensor 27 unit. Pellets were prepared by first mixing dry $\mathrm{KBr}$ with samples at a weight ratio of 300:1 and then cold pressing under $10 \mathrm{MPa}$. The spectra were created after 16 scans on average in transmission mode with $4 \mathrm{~cm}^{-1}$ of resolution. Raman spectra were recorded using a confocal Raman microscope (Via-Renishaw plc, UK) at a laser excitation wavelength of $532 \mathrm{~nm}$. A scanning electron microscope (SEM, Hitachi, S4800) and a transmission electron microscope (TEM, Titan $\mathrm{G}^{2}$ 60-300FEI, $80 \mathrm{kV}$ ) were used to observe the morphology and microstructure of the samples. For SEM measurements, the powders were dispersed on electrically conducting adhesive tapes in a glove box and rapidly transferred into the SEM chamber under protective Ar. For TEM examination, the powders were dispersed on $\mathrm{Cu}$ grids which were then loaded in

a double tilt vacuum transfer holder (Gatan 648, USA). X-ray photoelectron spectroscopy (XPS) analyses were carried out using a Kratos AXIS Ultra DLD spectrometer. The powders were first pressed into a pellet and then mounted on a sample holder inside an Ar-filled glove box. The sample holder was then transferred 
from the glove box to the XPS facility in a special container to avoid air exposure. The XPS data were recorded using a monochromatic Al K $\alpha$ X-ray source with a base pressure of $6.8 \times 10^{-9}$ Torr at $25^{\circ} \mathrm{C}$. All binding energies were calibrated using contaminant carbon $(\mathrm{C} 1 \mathrm{~s}=284.6 \mathrm{eV})$. Solid-state ${ }^{11} \mathrm{~B}$ and ${ }^{7} \mathrm{Li}$ magic angle spinning nuclear magnetic resonance (MAS NMR) analysis was performed on a Bruker AVANCE 400 III HD spectrometer equipped with a $3.2 \mathrm{~mm}$ MAS NMR probe. The powders were packed into a $3.2 \mathrm{~mm} \mathrm{ZrO}_{2}$ rotor and sealed with a tightly fitted Kel-F cap inside an Ar-filled glove box. The operating frequencies for ${ }^{11} \mathrm{~B}$ and ${ }^{7} \mathrm{Li}$ were 128.38 and 116.6 MHz, and the NMR shifts were reported in parts per million (ppm) referenced to $\mathrm{BF}_{3} \mathrm{OEt}_{2}$ and $\mathrm{LiClO}_{4}$, respectively. Elemental analysis was performed with an Elemen Tar Vario EL3 Elemental Analyser.

\subsection{Property measurements}

The dehydrogenation behavior was qualitatively evaluated using a home-built temperature-programmed desorption (TPD) system attached to a mass spectrometer (Hiden QIC-20, England). Pure Ar with a flow rate of $40 \mathrm{~mL} \mathrm{~min}{ }^{-1}$ was used as a carrier gas. For each test, the sample was heated from room temperature to $600{ }^{\circ} \mathrm{C}$ at $2{ }^{\circ} \mathrm{C} \min ^{-1}$. A home-made Sieverts-type apparatus was used for the quantitative measurement of dehydrogenation/hydrogenation under isothermal or non-isothermal conditions. The sample amount for each measurement was approximately $70 \mathrm{mg}$. The non-isothermal volumetric hydrogen release was conducted under primary vacuum $\left(\sim 10^{-3}\right.$ Torr $)$ with a temperature ramping at $2{ }^{\circ} \mathrm{C} \mathrm{min}^{-1}$, whereas hydrogenation was carried out at a heating rate of $1{ }^{\circ} \mathrm{C} \mathrm{min}-1$ under 100 bar $\mathrm{H}_{2}$. The isothermal measurements were conducted by rapidly heating $\left(10{ }^{\circ} \mathrm{C} \min ^{-1}\right)$ the sample to a preset temperature and then dwelling at the temperature during the entire test. The hydrogen capacity was calculated by taking into account the weight of the whole composite. 
Thermogravimetric analysis (TG) measurements were carried out using a NETZSCH TG $209 \mathrm{~F} 3$ instrument with a Ar flow of $60 \mathrm{~mL} \mathrm{~min}{ }^{-1}$ in the glove box, and the heating rates were identical to the volumetric experiments for non-isothermal and isothermal dehydrogenation, respectively. Differential scanning calorimetry (DSC) measurement was performed on a NETZSCH DSC 200F3 unit. Approximately 2 mg of sample was placed in an $\mathrm{Al}_{2} \mathrm{O}_{3}$ crucible and heated from $30{ }^{\circ} \mathrm{C}$ to $600{ }^{\circ} \mathrm{C}$ at $2{ }^{\circ} \mathrm{C}$ $\min ^{-1}$. The melting behaviour of samples was measured with a Mettler Toledo MP50 melting point apparatus. Samples were compacted into the quartz capillary and sealed with the scotch tape before the measurements. The sample temperature and melting process of the sample was recorded at the constant heating rate of $2{ }^{\circ} \mathrm{C} \min ^{-1}$.

\section{Results and discussion}

\subsection{Preparation and structural characterization of $\mathrm{LiBH}_{4}$ nanocomposite}

Fig. 1 schematically illustrates the one-pot solvothermal process to prepare $\mathrm{Ni}$ nanocrystal-decorated $\mathrm{LiBH}_{4}$ nanoparticles anchored on graphene. In a typical procedure, $n$-butyllithium (n-BuLi), triethylamine borane $\left(\left(\mathrm{C}_{2} \mathrm{H}_{5}\right)_{3} \mathrm{NBH}_{3}\right)$, nickelocene $\left(\mathrm{C}_{10} \mathrm{H}_{10} \mathrm{Ni}, \mathrm{Cp}_{2} \mathrm{Ni}\right.$ for short $)$ and graphene were first dispersed in $\mathrm{n}$-hexane with sonication for $2 \mathrm{~h}$. After that, the mixture solution was transferred into a customdesigned stainless steel autoclave and a solvothermal reaction was conducted under 50 bar $\mathrm{H}_{2}$ at $100{ }^{\circ} \mathrm{C}$ for $24 \mathrm{~h}$ with a continuous stirring. During the solvothermal reaction, n-BuLi was converted to $\mathrm{LiH}$ by hydriding (reaction 1) [34], which subsequently reacted with $\mathrm{C}_{6} \mathrm{H}_{15} \mathrm{NBH}_{3}$ yielding $\mathrm{LiBH}_{4} \cdot \mathrm{C}_{6} \mathrm{H}_{15} \mathrm{~N}$ (reaction 2) [38]. In parallel, metallic $\mathrm{Ni}$ was generated from the hydrogenation of $\mathrm{Cp}_{2} \mathrm{Ni}$ (reaction 3) [39]. All these reactions are known to take place with high yields. After filtering, washing with n-hexane and heating at $90{ }^{\circ} \mathrm{C}$ under dynamic vacuuming to remove solvent and 
$\mathrm{C}_{6} \mathrm{H}_{15} \mathrm{~N}$ groups (reaction 4), the resultant solid products were collected and characterized.

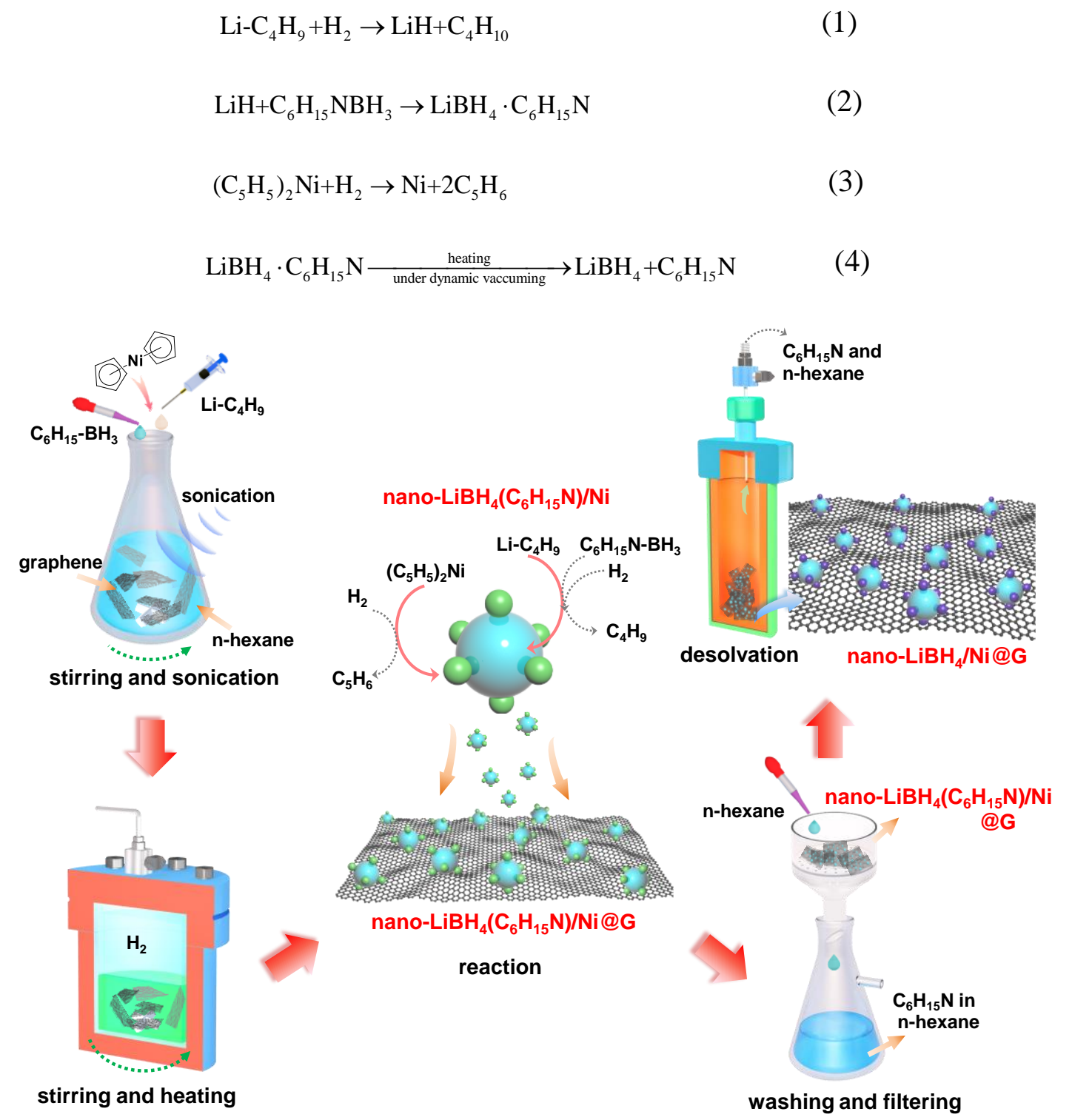

Fig. 1. Schematic illustration of the preparation of nano-LiBH $4 / \mathrm{Ni} @ \mathrm{G}$ composite.

Structural and morphological characterization results of the product are shown in Fig. 2. X-ray diffraction (XRD) pattern consists of the characteristic reflections of $\mathrm{LiBH}_{4}$. The weak peak intensities indicate the very small crystallite sizes (Fig. 2a). Fourier transform infrared spectroscopy (FTIR) spectrum further confirms the formation of $\mathrm{LiBH}_{4}$ since the typical absorbances of $\mathrm{B}-\mathrm{H}$ in $\mathrm{LiBH}_{4}$ are highly 
discernable at 1122, 2221, 2291 and $2380 \mathrm{~cm}^{-1}$ (Fig. 2b) [33]. IR absorbances related to C-H (at 3300-2700 $\mathrm{cm}^{-1}$ ) and N-H (at 3000-3500 $\mathrm{cm}^{-1}$ ) are absent in the IR spectra, proving the success in removing all organic molecules from the prepared $\mathrm{LiBH}_{4}$. Raman analysis reveals the typical D-band and G-band of graphene (Fig. 2c). Highresolution Ni 2p X-ray photoelectron spectrum (XPS) shows two peaks at 870.1 and $852.7 \mathrm{eV}$ (Fig. 2d), which can be assigned to the $2 \mathrm{p}_{1 / 2}-2 \mathrm{p}_{3 / 2}$ spin-orbit doublet of metallic $\mathrm{Ni}(0)$ [40]. Moreover, the $\mathrm{N}$ signal is invisible in the XPS survey spectrum (Fig. S1), indicating the complete removal of $\mathrm{C}_{6} \mathrm{H}_{15} \mathrm{~N}$. Mass spectroscopy (MS) measurement also confirms the absence of $\mathrm{C}_{6} \mathrm{H}_{15} \mathrm{~N}$ and $\mathrm{C}_{6} \mathrm{H}_{14}$ in the obtained $\mathrm{LiBH}_{4}$ powders (Fig. S2). These results unambiguously prove that the resultant product is composed of $\mathrm{LiBH}_{4}$, graphene and metallic Ni.
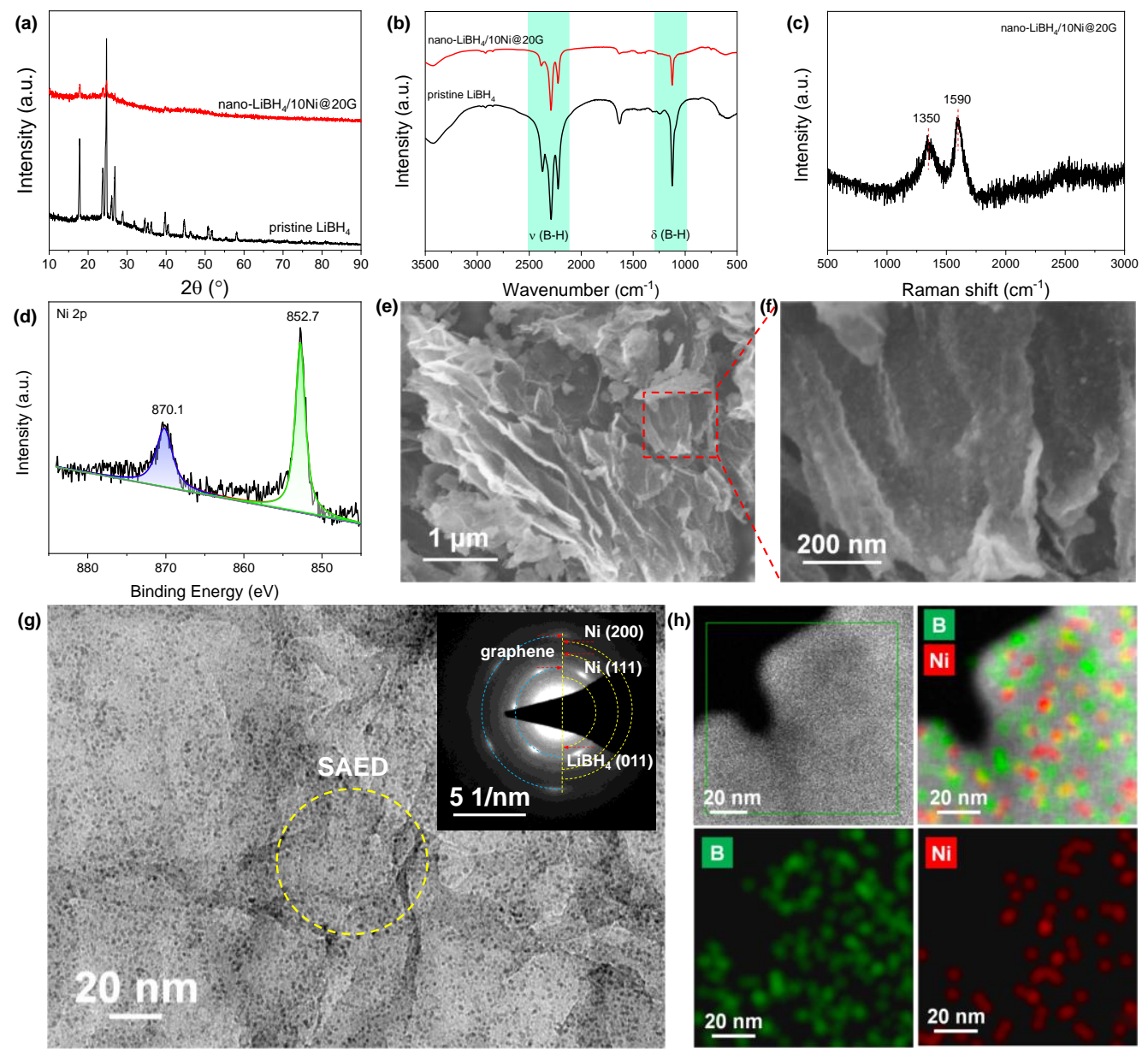

Fig. 2. XRD patterns (a) and FTIR spectra (b) of pristine $\mathrm{LiBH}_{4}$ and nano- 
$\mathrm{LiBH}_{4} / 10 \mathrm{Ni} @ 20 \mathrm{G}$; Raman spectra (c); high resolution Ni 2p XPS spectra (d); SEM images (e,f), TEM image (g), and EDS mapping images (h) of nano$\mathrm{LiBH}_{4} / 10 \mathrm{Ni} @ 20 \mathrm{G}$. The insert in $(\mathrm{g})$ is the SAED pattern.

Scanning electron microscope (SEM) and transmission electron microscope (TEM) observation reveals the typical graphene wrinkles on which a large amount of nanoparticles stay (Fig. 2e-g) while the commercial graphene displays a clean surface (Fig. S3). The SAED pattern in Fig. 2g indicates the polycrystalline characteristics of the resultant $\mathrm{LiBH}_{4}$ and $\mathrm{Ni}$ nanoparticles. Energy dispersive X-ray spectroscopy (EDS) mapping proves that nickel is distributed alongside boron (Fig. 2h), indicating a close physical contact between $\mathrm{Ni}$ and $\mathrm{LiBH}_{4}$. High-resolution TEM (HRTEM) images show two kinds of nanoparticles in grey and black with particle sizes being 5$10 \mathrm{~nm}$ and 2-4 nm, respectively (Fig. 3a). The grey nanoparticles were measured to have an interplanar spacing of $0.372 \mathrm{~nm}$, which is associated with the (011) planes of $\mathrm{LiBH}_{4}$ (Fig. 3b and c). The black nanoparticles display fringes with an interplanar spacing of $0.204 \mathrm{~nm}$, which can be assigned to the (111) lattice spacing of metallic $\mathrm{Ni}$ (Fig. 3d) [41]. Moreover, the HRTEM images also manifest the close contact and even overlapping between $\mathrm{Ni}$ nanoparticles and the $\mathrm{LiBH}_{4}$ particles. Thus, we obtained a unique composite consisting of $\mathrm{Ni}$ nanocrystal-decorated $\mathrm{LiBH}_{4}$ nanoparticles anchored on graphene. The corresponding yield of $\mathrm{LiBH}_{4}$ was determined to be approximately $96.8 \%$. 
(a)

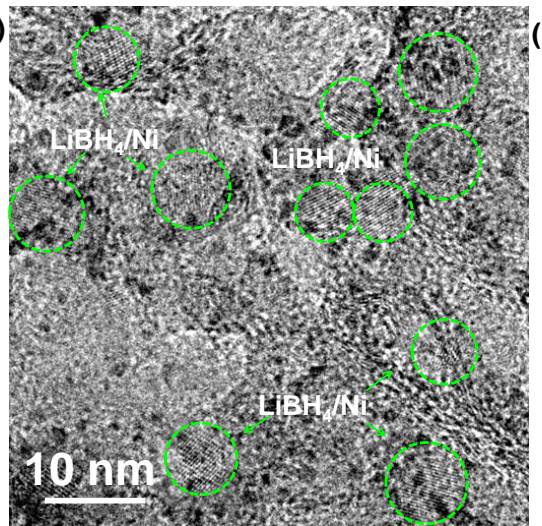

(c)

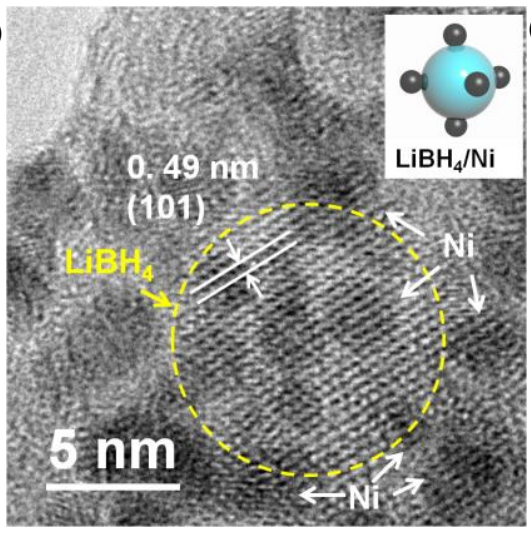

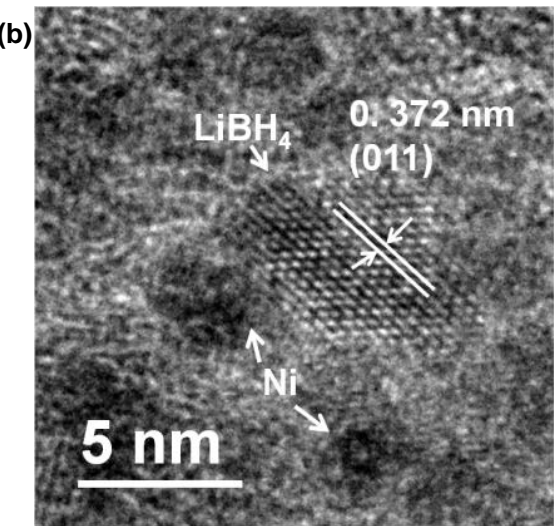

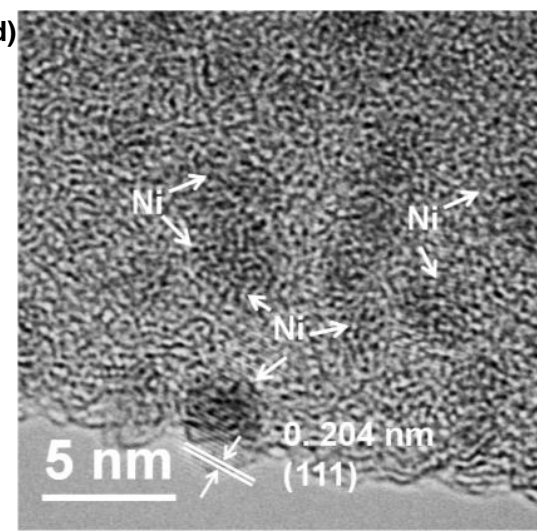

Fig. 3. HRTEM images of nano-LiBH $4 / 10 \mathrm{Ni} @ 20 \mathrm{G}$ composites (a-c) and $\mathrm{Ni}$ nanoparticles (d).

\subsection{Formation of $\mathrm{LiBH}_{4}$ nanoparticles with graphene}

To understand the formation of $\mathrm{LiBH}_{4}$ nanoparticles, the relationship between the graphene content and the particle sizes of resultant $\mathrm{LiBH}_{4}$ was further studied (Fig. 4). The results indicate that the presence of graphene is particularly important for obtaining nano-sized $\mathrm{LiBH}_{4}$. As shown in Fig. 4a-c, without graphene, large agglomerations of $\mathrm{LiBH}_{4}$ were observed using the same preparation procedure. For the $20 \mathrm{wt} \%$ graphene-containing sample, the particle sizes of $\mathrm{LiBH}_{4}$ are below $30 \mathrm{~nm}$ with good dispersion (Fig. 4m-o), which were further reduced to below $10 \mathrm{~nm}$ after increasing the graphene to $40 \mathrm{wt} \%$. This could be attributed to the large amounts of nucleation sites present on the graphene surface that prevent the agglomeration and growth of $\mathrm{LiBH}_{4}$ nanoparticles [34], consistent with the observation in the graphene- 
supported $\mathrm{MgH}_{2}$ system [42]. Furthermore, the Ni particles seem to also play a role in suppressing the growth of $\mathrm{LiBH}_{4}$ nanoparticles, as the particle sizes of $\mathrm{LiBH}_{4}$ in nano$\mathrm{LiBH}_{4} / 10 \mathrm{Ni} @ 20 \mathrm{G}$ (with 20 wt\% graphene, Fig. 3c) are remarkably smaller than those in Ni-free $\mathrm{LiBH}_{4} @ 20 \mathrm{G}$ (Fig. 4i). Considering the close contact between the ultrasmall $\mathrm{Ni}$ particles and $\mathrm{LiBH}_{4}$ nanoparticles (Fig. 3c and d), the growth and coalescence of $\mathrm{LiBH}_{4}$ particles would be retarded since they need to overcome the adhesion between $\mathrm{Ni}$ and graphene, which is a crucial factor favoring hydrogen cycling of $\mathrm{LiBH}_{4}$ as discussed later.
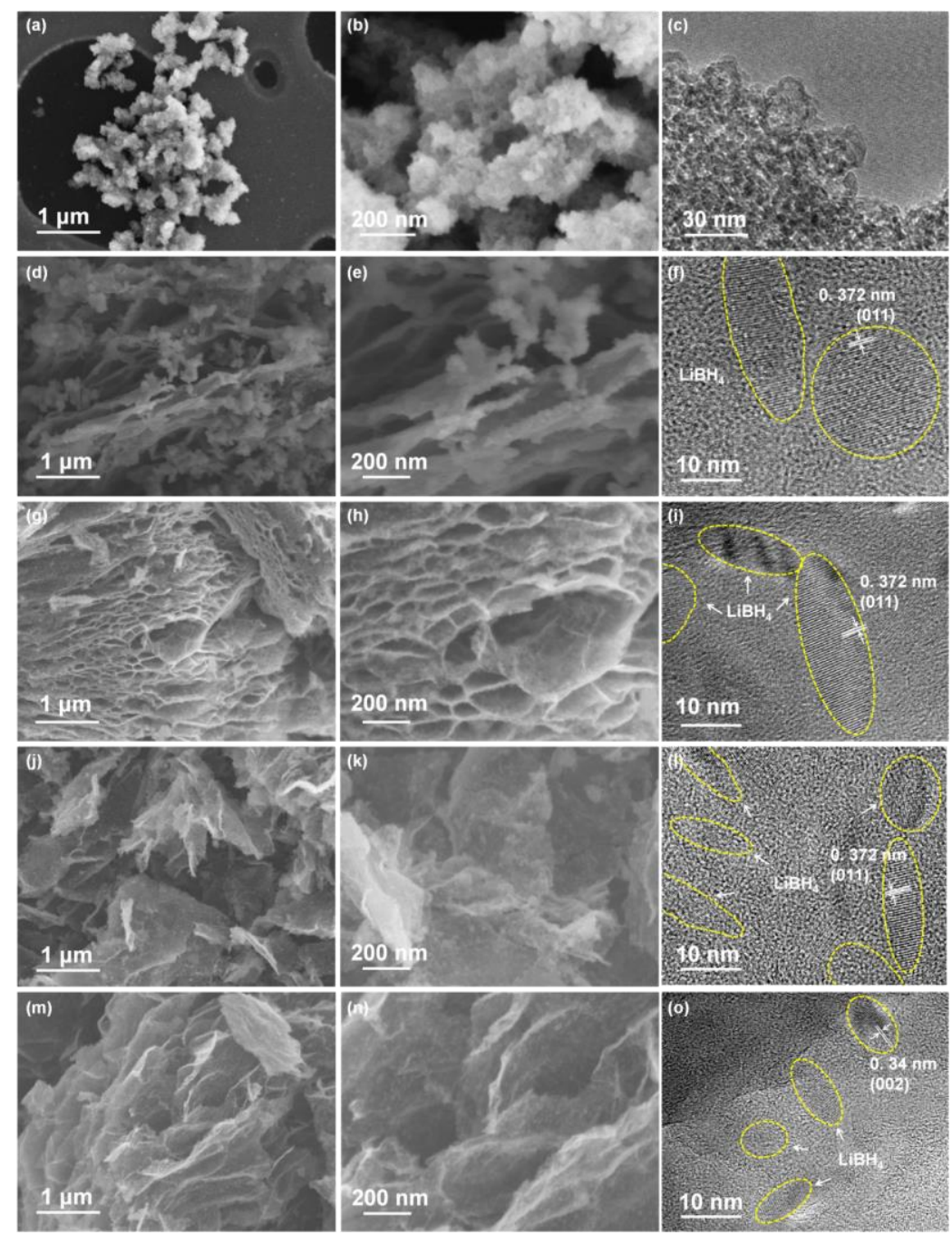

Fig. 4. SEM (a, b, d, e, g, h, j, k, m, n) and TEM (c, f, i, l, o) images of prepared nano$\mathrm{LiBH}_{4}$ with different graphene contents. (a-c) without graphene, (d-f) $10 \mathrm{wt} \% \mathrm{G},(\mathrm{g}-\mathrm{i})$ $20 \mathrm{wt} \% \mathrm{G},(\mathrm{j}-1) 30 \mathrm{wt} \% \mathrm{G}$ and (m-o) $40 \mathrm{wt} \% \mathrm{G}$. 


\subsection{Composition optimization of $\mathrm{LiBH}_{4}$ nanocomposite}

To optimize hydrogen capacity and operation temperature, we synthesized two series of samples with different amounts of graphene and metallic Ni. As shown in Fig. S4, compared with pristine $\mathrm{LiBH}_{4}, \mathrm{LiBH}_{4} /$ graphene nanocomposites feature much reduced dehydrogenation temperatures and also lowered hydrogen capacities since graphene does not hold $\mathrm{H}_{2}$. Balancing the temperatures and capacities, the sample with $70 \mathrm{wt} \% \mathrm{LiBH}_{4}$ and $30 \mathrm{wt} \%$ graphene exhibits the best overall performance. The in situ introduction of metallic $\mathrm{Ni}$ further reduces the dehydrogenation temperature (Fig. S5), similar to the previous report in the $\mathrm{CeH}_{2.73-}$ $\mathrm{MgH}_{2}-\mathrm{Ni}$ nanocomposites [43]. Replacing $10 \mathrm{wt} \%$ graphene with metallic Ni reduced the onset temperature of dehydrogenation by $>40{ }^{\circ} \mathrm{C}$. Considering the practical requirement of dehydrogenation temperatures (as low as possible) and hydrogen capacities (as high as possible), among all the $\mathrm{LiBH}_{4} /$ graphene/metallic Ni composites, the sample with approximately 70:20:10 for $\mathrm{LiBH}_{4}$ :graphene:Ni (denoted as nano$\left.\mathrm{LiBH}_{4} / 10 \mathrm{Ni} @ 20 \mathrm{G}\right)$ delivered the best overall performance.

\subsection{Hydrogen storage properties of nnao-LiBH4/10Ni@20G}

The nano-LiBH $/ 10 \mathrm{Ni@20G} \mathrm{composite} \mathrm{displays} \mathrm{remarkable} \mathrm{hydrogen} \mathrm{cycling}$ performance, outperforming all the literature results reported so far. The temperatureprogrammed desorption - mass spectroscopy (TPD-MS) curve displays the liberation of hydrogen without $\mathrm{B}_{2} \mathrm{H}_{6}$ impurity with temperatures (Fig. 5a and Fig. S6). Dehydrogenation started from $130{ }^{\circ} \mathrm{C}$ and peaked around $285^{\circ} \mathrm{C}$, which are 175 and $192{ }^{\circ} \mathrm{C}$ lower than those of the pristine $\mathrm{LiBH}_{4}$ (Fig. 5a). Volumetric measurements determined that nano- $\mathrm{LiBH}_{4} / 10 \mathrm{Ni} @ 20 \mathrm{G}$ released 11.6 wt $\%$ hydrogen (in overall composite mass) when heated to $600{ }^{\circ} \mathrm{C}$, with an onset temperature of $130{ }^{\circ} \mathrm{C}$ and acceleration from $175^{\circ} \mathrm{C}$, significantly lower than those of pristine $\mathrm{LiBH}_{4}$ and $\mathrm{Ni}$-free 
nano-LiBH 4 @G (Fig. 5b). The sluggish hydrogen release above $315^{\circ} \mathrm{C}$ was possibly related to the decomposition of in-situ formed $\mathrm{LiH}$, which is known to form during the dehydrogenation of $\mathrm{LiBH}_{4}$ [13]. This hypothesis is supported by the appearance of XPS 1s peak of metallic Li in the powders after dehydrogenation at $315^{\circ} \mathrm{C}$ (Fig. S7). We found that if the dehydrogenation was conducted at temperatures beyond $300{ }^{\circ} \mathrm{C}$, the subsequent hydrogenation performance became inferior (Fig. S8a and b). This is possibly due to the aggregation of molten metallic $\mathrm{Li}$ generated from the dehydrogenation of in-situ formed $\mathrm{LiH}$, which leads to reduced reactivity of $\mathrm{Li}$. As a result, the maximum desorption temperature was chosen to be $300{ }^{\circ} \mathrm{C}$ and a reversible hydrogen capacity of 9.2 wt\% was obtained (Fig. S8c and d). Such dehydrogenation performance outperforms most materials-based hydrogen carriers taking into account dehydrogenation capacity and temperature (Fig. S9). Different from pristine $\mathrm{LiBH}_{4}$, $\mathrm{B}_{2} \mathrm{H}_{6}$ gas was not detected during dehydrogenation (Fig. S6), which is beneficial for reversible hydrogen cycling by keeping the atomic ratio of $\mathrm{B}: \mathrm{Li}$ at $1: 1$ to ensure full regeneration.
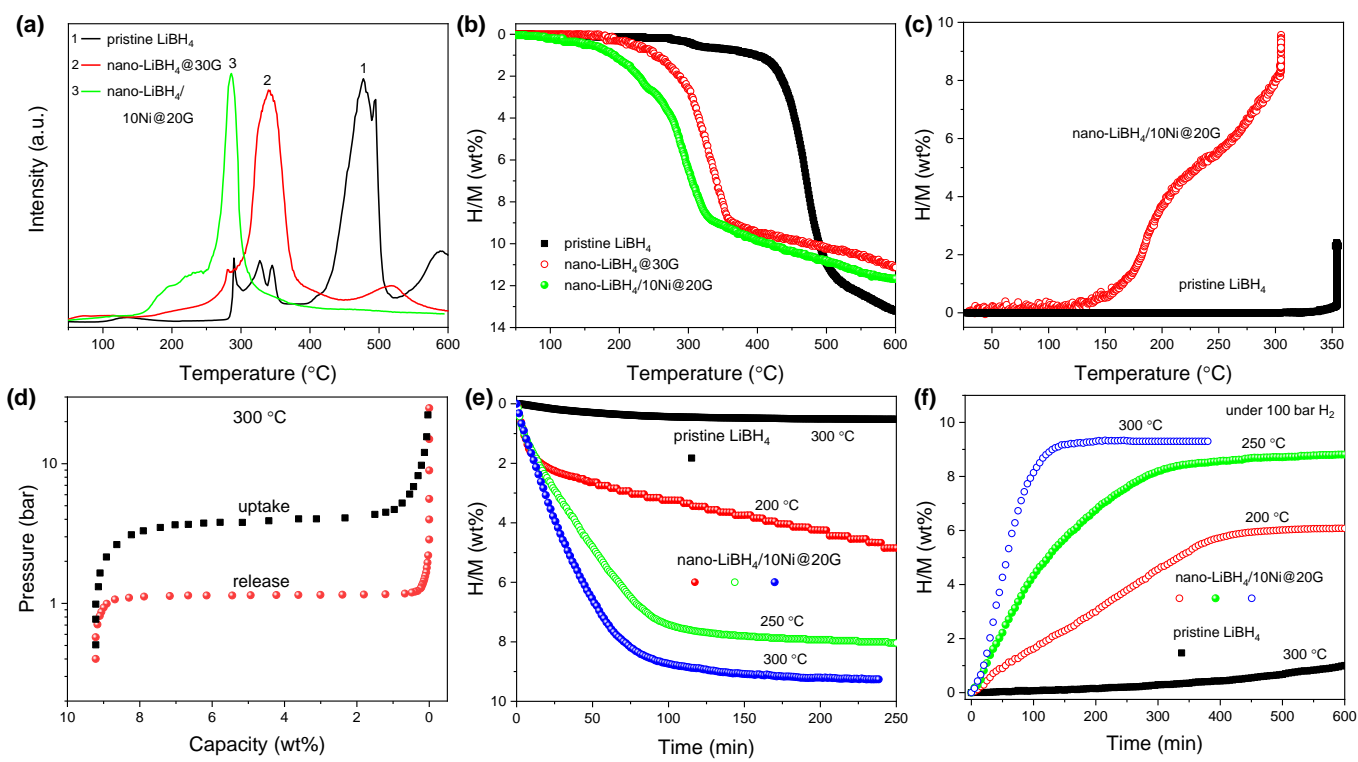
Fig. 5. TPD-MS (a), volumetric hydrogen release (b), non-isothermal hydrogenation (c), PCI (d), isothermal dehydrogenation (e) and isothermal hydrogenation (f) curves of nano- $\mathrm{LiBH}_{4} / 10 \mathrm{Ni} @ 20 \mathrm{G}$ and pristine $\mathrm{LiBH}_{4}$.

The nano-LiBH $4 / 10 \mathrm{Ni} @ 20 \mathrm{G}$ also demonstrates exceptional hydrogenation performance under 100 bar $\mathrm{H}_{2}$. As shown in Fig. 5c, hydrogenation started from $125{ }^{\circ} \mathrm{C}$, which is $200{ }^{\circ} \mathrm{C}$ lower than that of dehydrogenated pristine $\mathrm{LiBH}_{4}$. Upon heating to $300{ }^{\circ} \mathrm{C}$, hydrogen uptake amounts to $9.2 \mathrm{wt} \%$, showing a good reversibility for hydrogen storage. This is superior to all presently known $\mathrm{LiBH}_{4}$-based hydrogen storage systems (Fig. S9 and Table S1). The significantly improved hydrogen storage reversibility was also confirmed by pressure-composition-isotherm (PCI) measurements carried out at $300{ }^{\circ} \mathrm{C}$ (Fig. 5d), a temperature much lower than reported [44]. More importantly, the desorption equilibrium pressure was determined to be 1.14 atm at $300{ }^{\circ} \mathrm{C}$ (Fig. 5d). In contrast, the pristine $\mathrm{LiBH}_{4}$ requires $370{ }^{\circ} \mathrm{C}$ to reach 1 atm of desorption equilibrium pressure [44]. This indicates that thermodynamic stability was effectively lowered possibly due to the largely reduced particle size of $\mathrm{LiBH}_{4}$ with the presence of graphene and $\mathrm{Ni}$ [45].

Further isothermal measurements in a closed system prove significantly improved kinetics in hydrogen cycling at lower temperatures (Fig. 5e and f). At $300{ }^{\circ} \mathrm{C}$, approximately $9.2 \mathrm{wt} \%$ of hydrogen was released within $175 \mathrm{~min}$, with an average dehydrogenation rate of $0.053 \mathrm{wt} \% \mathrm{~min}^{-1}$ (Fig. 5e). In contrast, no hydrogen release was detected for the pristine $\mathrm{LiBH}_{4}$ under an identical condition. In TGA mode (Fig. S10) where a constant flow of pure Ar is used as a carrier gas, the amount of hydrogen release increased to $10 \mathrm{wt} \%$ within $75 \mathrm{~min}$ due to the absence of equilibrium pressure limitation. Even at $200{ }^{\circ} \mathrm{C}$, the nano-LiBH $4 / 10 \mathrm{Ni} @ 20 \mathrm{G}$ released 
$7.5 \mathrm{wt} \%$ hydrogen within $600 \mathrm{~min}$, superior to the previous reports (Table S1). In the hydrogenation step, the dehydrogenated nano-LiBH $4 / 10 \mathrm{Ni} @ 20 \mathrm{G}$ sample absorbed 9.2 wt $\%$ of hydrogen within 200 min under 100 bar $\mathrm{H}_{2}$ and $300{ }^{\circ} \mathrm{C}$ (Fig. 5f), whereas only $2.3 \mathrm{wt} \%$ of hydrogen was recharged into the dehydrogenated pristine $\mathrm{LiBH}_{4}$ even at $350{ }^{\circ} \mathrm{C}$ for $1200 \mathrm{~min}$ (Fig. S11).

\subsection{Dehydrogenation thermodyanmics and kinetics of nano-LiBH4/10Ni@20G}

The dehydrogenation thermodynamics and kinetics of nano- $\mathrm{LiBH}_{4} / 10 \mathrm{Ni} @ 20 \mathrm{G}$ were further characterized in terms of desorption heat and the apparent activation energy, respectively. A phase transformation was observed at around $110^{\circ} \mathrm{C}$, which is similar to the literature [46]. However, the endothermic peak corresponding to hydrogen desorption shifted considerably toward lower temperatures (Fig. 6a). Unlike pristine $\mathrm{LiBH}_{4}$, melting was not detected for nano-LiBH $4 / 10 \mathrm{Ni@20G} \mathrm{during}$ dehydrogenation since the morphology remained the same as temperatures increased (Fig. S12). In contrast to an increase in the light transmittance due to the melting of $\mathrm{LiBH}_{4}$ forming a liquid, nano-LiBH $/ 10 \mathrm{Ni} @ 20 \mathrm{G}$ displayed decreased light transmittance caused by the formation of $\mathrm{B}$ due to the dehydrogenation of $\mathrm{LiBH}_{4}(\mathrm{Fig}$. S13). The suppression of melting is of significance in maintaining highly dispersed nanoparticles that contribute to high hydrogen cycling performance. The enthalpy change of hydrogen desorption from nano-LiBH $4 / 10 \mathrm{Ni} @ 20 \mathrm{G}$ was calculated to be approximately $62.1 \mathrm{~kJ} \mathrm{~mol}^{-1}-\mathrm{H}_{2}$, about $10 \%$ lower than that of pristine $\mathrm{LiBH}_{4}(69 \mathrm{~kJ}$ $\mathrm{mol}^{-1}-\mathrm{H}_{2}$ ), a remarkable change in the thermodynamics. The apparent activation energy was estimated as $106 \mathrm{~kJ} \mathrm{~mol}^{-1}$ using the Kissinger's approach (Fig. 6b), $73 \mathrm{~kJ}$ mol ${ }^{-1}$ lower than that of pristine $\mathrm{LiBH}_{4}$ [35]. Thus, nano-LiBH $4 / 10 \mathrm{Ni} @ 20 \mathrm{G}$ features much enhanced thermodynamics and kinetics and consequently significantly improved hydrogen cycling compared with neat $\mathrm{LiBH}_{4}$. 

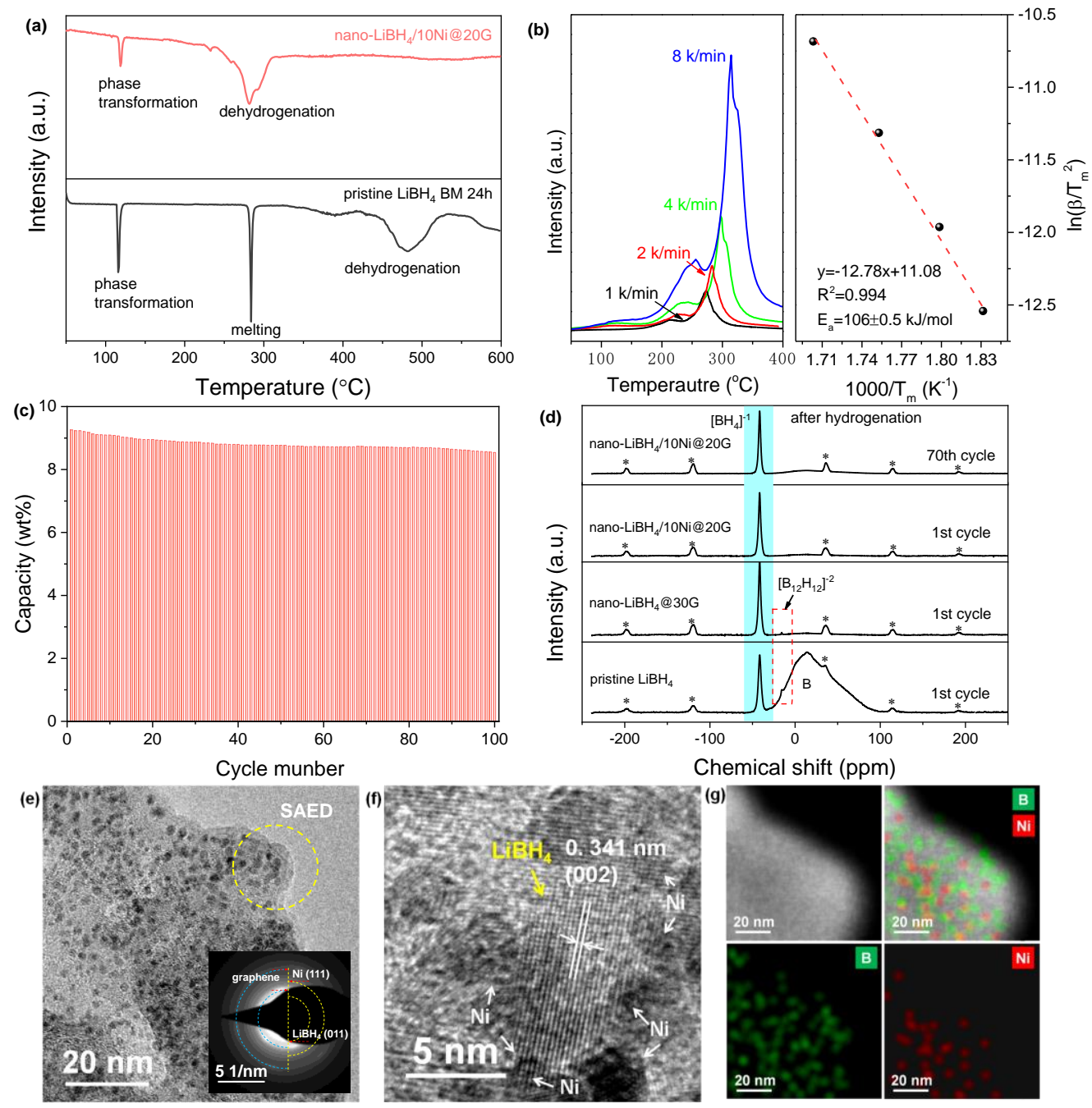

Fig. 6. DSC curves (a), TPD-MS curves and corresponding Kissinger's plots (b), hydrogen cycling stability (c), solid state ${ }^{11} \mathrm{~B}$ NMR spectra (d), TEM image (e), HRTEM image (f), and EDS mapping (g) images of nano-LiBH $4 / 10 \mathrm{Ni@20G}$ after 70 cycles. The peaks marked with * in (d) indicate the spinning sidebands and the insert in (e) is the SAED pattern.

The hydrogen cycling stability is critical for practical applications. Fig. 6c shows the isothermal dehydrogenation capacity of nano- $\mathrm{LiBH}_{4} / 10 \mathrm{Ni} @ 20 \mathrm{G}$ as a function of cycle at $300{ }^{\circ} \mathrm{C}$. After 100 cycles, the hydrogen capacity is around $8.5 \mathrm{wt} \%$, corresponding to $92.4 \%$ of capacity retention, which is superior to all the reported $\mathrm{LiBH}_{4}$-based hydrogen storage systems (Table S1). Furthermore, the dehydrogenation 
kinetics remains nearly unchanged upon cycling (Fig. S14). Detailed studies were carried out to understand the underlying reason for the remarkable cycling stability and kinetics. As shown in Fig. S15-17, XRD, FTIR and NMR results indicate that with increasing temperature, the characteristic signals of $\mathrm{LiBH}_{4}$ gradually weakened and eventually disappeared at $375{ }^{\circ} \mathrm{C}$, indicating a complete decomposition of $\mathrm{LiBH}_{4}$ with the release of hydrogen. Here, it should be mentioned that $375^{\circ} \mathrm{C}$ is higher than the $300{ }^{\circ} \mathrm{C}$ used for isothermal hydrogen cycling. This is because due to slow kinetics, under a $2{ }^{\circ} \mathrm{C} / \mathrm{min}$ ramping rate, $\mathrm{LiBH}_{4}$ does not decompose quickly enough; while dwelling at $300{ }^{\circ} \mathrm{C}$ for more than 150 mins leads to a complete dehydrogenation. In general, borohydrides are known to release $\mathrm{B}_{2} \mathrm{H}_{6}$ to different degrees during thermal decomposition [7]. Our results also confirm this phenomenon for pristine $\mathrm{LiBH}_{4}$ (Fig. S6). For nano- $\mathrm{LiBH}_{4} / 10 \mathrm{Ni} @ 20 \mathrm{G}$, however, only $\mathrm{H}_{2}$ was observed in the MS spectra without $\mathrm{B}_{2} \mathrm{H}_{6}$. This is consistent with reports that the presence of nanosized metal catalyst can suppress the formation of $\mathrm{B}_{2} \mathrm{H}_{6}$ molecules, and therefore contribute to hydrogen cycling [16-21].

Moreover, $\mathrm{Li}_{2} \mathrm{~B}_{12} \mathrm{H}_{12}$ was not detected for nano- $\mathrm{LiBH}_{4} / 10 \mathrm{Ni} @ 20 \mathrm{G}$ during hydrogen cycling, even after 70 cycles (Fig. 6d). In sharp contrast, the formation of $\mathrm{B}_{12} \mathrm{H}_{12}{ }^{2-}$ was observed during hydrogenation of both $\mathrm{LiBH}_{4} @ 20 \mathrm{G}$ and pristine $\mathrm{LiBH}_{4}$, which have displayed far inferior hydrogen cycling performance (Fig. S18) compared with nano- $\mathrm{LiBH}_{4} / 10 \mathrm{Ni} @ 20 \mathrm{G}$. It is well known that $\mathrm{B}_{12} \mathrm{H}_{12}{ }^{2-}$ is highly stable and prevents $\mathrm{B}$ from forming $\mathrm{BH}_{4}^{-}$[47]. To achieve effective hydrogen cycling performance under mild conditions, it is important to keep boron active, i.e., preventing boron from dropping into the $\mathrm{B}_{12} \mathrm{H}_{12}{ }^{2-}$ 'sink'. The solvothermal method adopted in this work leads to in-situ formation of Ni nanoparticles which have close physical contacts with nanosized $\mathrm{LiBH}_{4}$ powders anchored on graphene, achieving 
nanostructuring and nanocatalysis simultaneously. Through a combination of nanostructuring and nanocatalysis, the dehydrogenation temperature of nano$\mathrm{LiBH}_{4} / 10 \mathrm{Ni} @ 20 \mathrm{G}$ was remarkably reduced and the release of hydrogen completed at around $300{ }^{\circ} \mathrm{C}$, which is lower than the temperature required to generate $\mathrm{B}_{2} \mathrm{H}_{6}$ (Fig. S6a). This reasonably explains the absence of $\mathrm{B}_{2} \mathrm{H}_{6}$ in Fig. S6b. Moreover, the absence of $\mathrm{B}_{2} \mathrm{H}_{6}$ is also critical in preventing the formation of $\mathrm{Li}_{2} \mathrm{~B}_{12} \mathrm{H}_{12}$ which originates from the reaction between $\mathrm{B}_{2} \mathrm{H}_{6}$ and $\mathrm{LiBH}_{4}$ at elevated temperatures $[24,47]$. As a result, the formation of both highly volatile $\mathrm{B}_{2} \mathrm{H}_{6}$ and highly stable $\mathrm{B}_{12} \mathrm{H}_{12^{2-}}$ are effectively suppressed in nano- $\mathrm{LiBH}_{4} / 10 \mathrm{Ni} @ 20 \mathrm{G}$, leading to unparalleled hydrogen cycling performance.

The outstanding stability of $\mathrm{Ni}$ also contributes to the exceptional hydrogen cycling. After 70 cycles, TEM images reveal no appreciable agglomeration of the $\mathrm{Ni}$ nanoparticles (Fig. 6e and f) and the EDS mapping (Fig. 6g) indicates that nanosized Ni particles still stick to $\mathrm{LiBH}_{4}$ particles, both of which are beneficial for cycling stability. High-resolution Ni 2p XPS spectra (Fig. 7a) indicate that the chemical state of $\mathrm{Ni}$ remains unchanged below $375{ }^{\circ} \mathrm{C}$, indicating its catalytic role during dehydrogenation and hydrogenation. XPS spectra also reveal that Ni and B did not form chemical bond unless the hydrogen cycling temperature went above $375^{\circ} \mathrm{C}$ (Fig. 7). Thus, with synergy of nanostructuring induced by graphene support and nanocatalysis originated from in-situ formed $\mathrm{Ni}$ nanocrystals with close physical contacts with $\mathrm{LiBH}_{4}$ nanoparticles, a facile interconversion between elemental B and $\mathrm{BH}_{4}{ }^{-}$has been achieved in our work by preventing the liberation of $\mathrm{B}_{2} \mathrm{H}_{6}$ and the formation of $\mathrm{B}_{12} \mathrm{H}_{12}{ }^{2-}$, which enables highly reversible hydrogen cycling at remarkably lowered temperatures. 

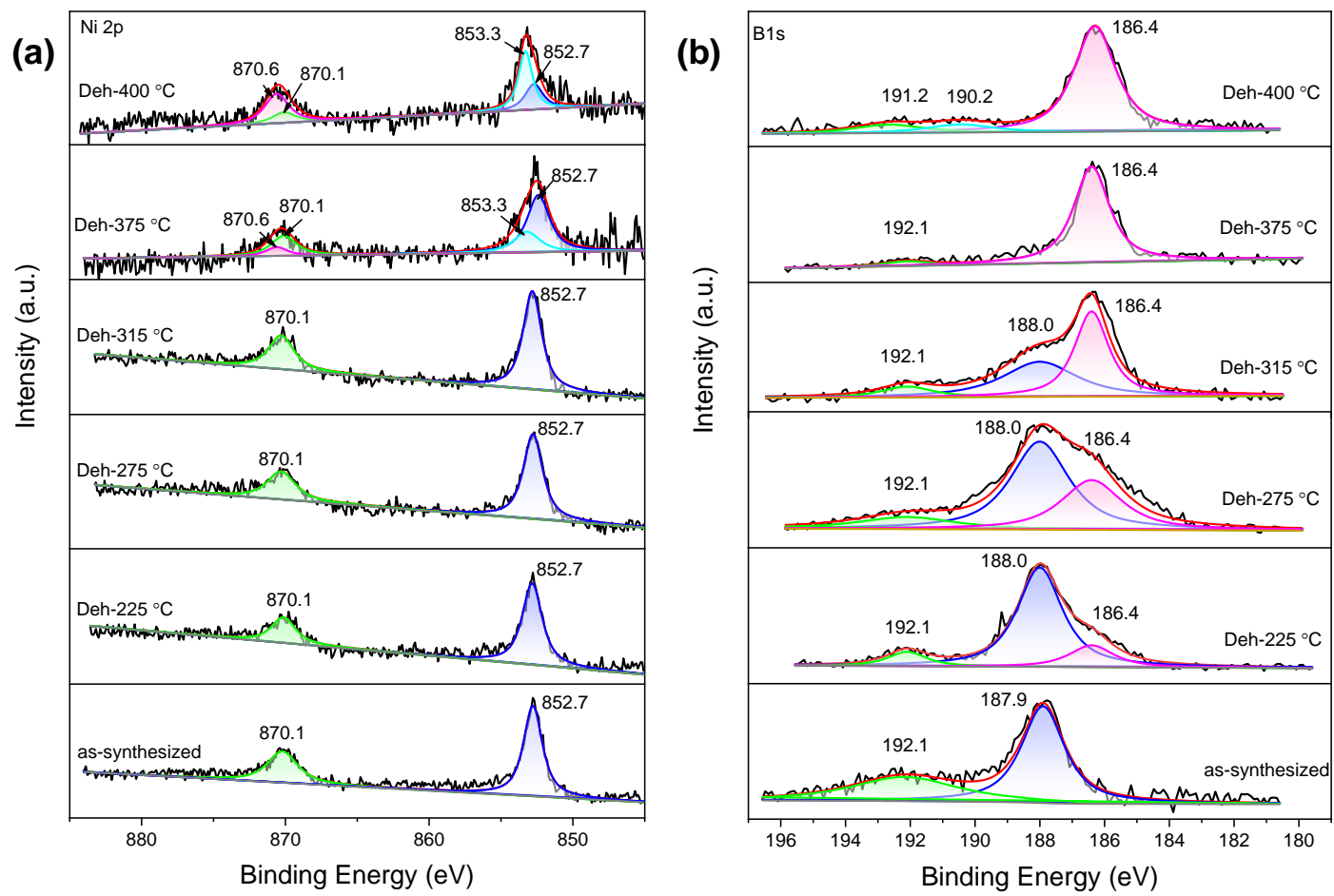

Fig. 7 High-resolution Ni 2p (a) and B 1s (b) XPS spectra of nano-LiBH $4 / 10 \mathrm{Ni@20G}$ at different dehydrogenation temperatures.

\section{Conclusion}

We have developed an effective strategy to achieve highly reversible hydrogen cycling for $\mathrm{LiBH}_{4}$ at lower temperatures. The key to the outstanding performance is to keep boron within the system (not forming volatile $\mathrm{B}_{2} \mathrm{H}_{6}$ ) and to maintain its reactivity (not forming thermally stable $\mathrm{B}_{12} \mathrm{H}_{12^{2-}}$ ). This superior performance is delivered by a unique nanocomposite where on graphene $\mathrm{LiBH}_{4}$ nanoparticles of 5-10 $\mathrm{nm}$ are decorated by Ni nanocrystals of 2-4 nm, which was successfully synthesized by a novel one-pot solvothermal process. Both graphene and Ni nanocrystals restrict the growth of $\mathrm{LiBH}_{4}$ nanoparticles during preparation process. The close contact among $\mathrm{Ni}$, graphene, and $\mathrm{LiBH}_{4}$ exerts highly effective catalytic effects on both dehydrogenation and rehydrogenation. The synergy of nanostructuring and 
nanocatalysis remarkably reduces the operation temperatures and effectively suppresses the formation of volatile $\mathrm{B}_{2} \mathrm{H}_{6}$ and stable $\mathrm{B}_{12} \mathrm{H}_{12}{ }^{2-}$. This breakthrough sheds light on how to improve the hydrogen cycling performance of borohydrides. In view of the large family of borohydrides, this research may help bring them one step closer to practical hydrogen storage applications.

\section{CRediT authorship contribution statement}

Xin Zhang: Conceptualization, Investigation, Writing-original draft; Lingchao Zhang: Investigation, Visualization; Wenxuan Zhang: Methodology; Zhuanghe Ren: Formal analysis; Zhenguo Huang: Formal analysis, Writing - review \& editing; Jianjiang Hu: Formal analysis, Writing - review \& editing; Mingxia Gao: Formal analysis, Methodology; Hongge Pan: Conceptualization, Resources; Yongfeng Liu: Conceptualization, Methodology, Resources, Writing - review \& editing.

\section{Declaration of Competing Interest}

The authors declare that they have no known competing financial interests or personal relationships that could have appeared to influence the work reported in this paper

\section{Acknowledgments}

This work was supported by the National Key R\&D Program of China (2018YFB1502102), the Natural Science Foundation of Zhejiang Province (LD21E010002), the National Natural Science Foundation of China (52001277, 52071287), and the National Youth Top-Notch Talent Support Program. Z.H. acknowledges support under the Australian Research Council's (ARC) Discovery 
Projects funding scheme (DP170101773) and an ARC Future Fellowship (FT190100658).

\section{Appendix A. Supporting information}

Supplementary data associated with this article can be found in the online version at doi:10.1016/

\section{References}

[1] L. Schlapbach, A. Züttel, Hydrogen-Storage Materials for Mobile Applications, Nature 414 (2001) 353-358.

[2] U. Eberle, M. Felderhoff, F. Schüth, Chemical and physical solutions for hydrogen storage, Angew. Chem. Int. Ed. 48 (2009) 6608-6630.

[3] T. He, P. Pachfule, H. Wu, Q. Xu, P. Chen, Hydrogen Carriers, Nat. Rev. Mater. $1(2016) 16059$.

[4] B. Sakintuna, F. Lamari-Darkrim, M. Hirscher, Metal Hydride Materials for Solid Hydrogen Storage: A Review, Int. J. Hydrogen Energy 32 (2007) 11211140.

[5] S. Orimo, Y. Nakamori, J. R. Eliseo, A. Züttel, C. M. Jensen, Complex Hydrides for Hydrogen Storage, Chem. Rev. 107 (2007) 4111-4132.

[6] H. M. Sun, J. Meng, L. F. Jiao, F. Y. Cheng, J. Chen, A review of transitionmetal boride/phosphide-based materials for catalytic hydrogen generation from hydrolysis of boron-hydrides, Inorg. Chem. Front. 5 (2018) 760-772.

[7] A. Züttel, P. Wenger, S. Rentsch, P. Sudan, P. Mauron, C. Emmenegger, $\mathrm{LiBH}_{4}$ A New Hydrogen Storage Material, J. Power Sources 118 (2003) 1-7. 
[8] L. Z. Ouyang, W. Chen, J. W. Liu, M. Felderhoff, H. Wang, M. Zhu, Enhancing the Regeneration Process of Consumed $\mathrm{NaBH}_{4}$ for Hydrogen Storage, Adv. Energy Mater. 7 (2017) 1700299.

[9] K. Chen, L. Z. Ouyang, H. Zhong, J. W. Liu, H. Wang, H. Y. Shao, Y. Zhang, M. Zhu, Converting $\mathrm{H}^{+}$from coordinated water into $\mathrm{H}^{-}$enables super facile synthesis of $\mathrm{LiBH}_{4}$, Green Chem. 21 (2019) 4380-4387.

[10] Y. Y. Zhu, L. Z. Ouyang, H. Zhong, J. W. Liu, H. Wang, H. Y. Shao, Z. G. Huang, M. Zhu, Closing the Loop for Hydrogen Storage: Facile Regeneration of $\mathrm{NaBH}_{4}$ from its Hydrolytic Product, Angew. Chem. Int. Ed. 59 (2020) 86238629.

[11] H. W. Li, Y. G. Yan, S. Orimo, A. Züttel, C. M. Jensen, Recent Progress in Metal Borohydrides for Hydrogen Storage, Energies 4 (2011) 185-214.

[12] L. H. Rude, T. K. Nielsen, D. B. Ravnsbæk, U. Bösenberg, M. B. Ley, B. Richter, L. M. Arnbjerg, M. Dornheim, Y. Filinchuk, F. Besenbacher, T. R. Jensen, Tailoring Properties of Borohydrides for Hydrogen Storage: A Review. Phys, Status Solidi A 208 (2011) 1754-1773.

[13] G. L. Xia, Y. B. Tian, F. L. Wu, F. Fang, Z. P. Guo, Z. G. Huang, X. B. Yu, Graphene-wrapped reversible reaction for advanced hydrogen storage, Nano Energy 26 (2016) 488-495.

[14] E. Callini, A. Borgschulte, A. J. Ramirez-Cuesta, A. Züttel, Diborane Release and Structure Distortion in Borohydrides, Dalton Trans. 42, (2013) 719-725.

[15] M. P. Pitt, M. Paskevicius, D. H. Brown, D. A. Sheppard, C. E. Buckley, Thermal Stability of $\mathrm{Li}_{2} \mathrm{~B}_{12} \mathrm{H}_{12}$ and its Role in the Decomposition of $\mathrm{LiBH}_{4}, \mathrm{~J}$. Am. Chem. Soc. 135 (2013) 6930-6941. 
[16] C. Li, P. Peng, D. W. Zhou, L. Wan, Research Progress in $\mathrm{LiBH}_{4}$ for Hydrogen Storage: A Review, Int. J. Hydrogen Energy 36 (2011) 14512-14526.

[17] J. Puszkiel, A. Gasnier, G. Amica, F. Gennari, Tuning $\mathrm{LiBH}_{4}$ for Hydrogen Storage: Destabilization, Additive, and Nanoconfinement Approaches, Molecules 25 (2020) 163.

[18] P. Javadian, D. A. Sheppard, C. E. Buckley, T. R. Jensen Hydrogen storage properties of nanoconfined $\mathrm{LiBH}_{4}-\mathrm{Ca}\left(\mathrm{BH}_{4}\right)_{2}$, Nano Energy 11 (2015) 96-103.

[19] D. Ravnsbæk, Y. Filinchuk, Y. Cerenius, H. J. Jakobsen, F. Besenbacher, J. Skibsted, T. R. Jensen, A Series of Mixed-Metal Borohydrides, Angew. Chem. Int. Ed. 48 (2009) 6659-6663.

[20] W. T. Cai, H. Wang, J. W. Liu, L. F. Jiao, Y. J. Wang, L. Z. Ouyang, T. Sun, D. L. Sun, H. H. Wang, X. D. Yao, M. Zhu, Towards Easy Reversible Dehydrogenation of $\mathrm{LiBH}_{4}$ by Catalyzing Hierarchic Nanostructured CoB, Nano Energy 10 (2014) 235-244.

[21] J. J. Vajo, S. L. Skeith, F. Mertens, Reversible Storage of Hydrogen in Destabilized $\mathrm{LiBH}_{4}$, J. Phys. Chem. B 109 (2005) 3719-3722.

[22] A. Schneemann, J. L. White, S. Y. Kang, S. Jeong, L. F. Wan, E. S. Cho, T. W. Heo, D. Prendergast, J. J. Urban, B. C. Wood, M. D. Allendorf, V. Stavila, Nanostructured Metal Hydrides for Hydrogen Storage, Chem. Rev. 118 (2018) $10775-10839$.

[23] X. B. Yu, Z. W. Tang, D. L. Sun, L. Z. Ouyang, M. Zhu, Recent Advances and Remaining Challenges of Nanostructured Materials for Hydrogen Storage Applications, Prog. Mater. Sci. 88 (2017) 1-48.

[24] X. F. Wan, L. L. Shaw, Novel dehydrogenation properties derived from nanoscale $\mathrm{LiBH}_{4}$, Acta Mater. 59 (2011) 4606-4615. 
[25] X. F. Liu, D. Peaslee, C. Z. Jost, T. F. Baumann, E. H. Majzoub, Systematic Pore-Size Effects of Nanoconfinement of $\mathrm{LiBH}_{4}$ : Elimination of Diborane Release and Tunable Behavior for Hydrogen Storage Applications, Chem. Mater. 23 (2011) 1331-1336.

[26] P. E. de Jongh, P. Adelhelm, Nanosizing and Nanoconfinement: New Strategies Towards Meeting Hydrogen Storage Goals, ChemSusChem 3 (2010) 1332 1348.

[27] T. K. Nielsen, F. Besenbacher, T. R. Jensen, Nanoconfined Hydrides for Energy Storage, Nanoscale 3 (2011) 2086-2098.

[28] A. F. Gross, J. J. Vajo, S. L. V. Atta, G. L. Olson, Enhanced Hydrogen Storage Kinetics of $\mathrm{LiBH}_{4}$ in Nanoporous Carbon Scaffolds, J. Phys. Chem. C 112 (2008) 5651-5657.

[29] P. Ngene, P. Adelhelm, A. M. Beale, K. P. de Jong, P. E. de Jongh, $\mathrm{LiBH}_{4} / \mathrm{SBA}-15$ Nanocomposites Prepared by Melt Infiltration under Hydrogen Pressure: Synthesis and Hydrogen Sorption Properties, J. Phys. Chem. C 114, (2010) 6163-6168.

[30] X. F. Liu, D. Peaslee, C. Z. Jost, E. H. Majzoub, Controlling the Decomposition Pathway of $\mathrm{LiBH}_{4}$ via Confinement in Highly Ordered Nanoporous Carbon, J. Phys. Chem. C 114 (2010) 14036-14041.

[31] L. L. Guo, Y. Li, Y. F. Ma, Y. Liu, D. D. Peng, L. Zhang, S. M. Han, Enhanced Hydrogen Storage Capacity and Reversibility of $\mathrm{LiBH}_{4}$ Encapsulated in Carbon Nanocages, Int. J. Hydrogen Energy 42 (2017) 2215-2222.

[32] P. Ngene, M. Van Zwienen, P. E. de Jongh, Reversibility of the Hydrogen Desorption from $\mathrm{LiBH}_{4}$ : a Synergetic Effect of Nanoconfinement and $\mathrm{Ni}$ Addition, Chem. Commun. 46 (2010) 8201-8203. 
[33] P. Ngene, M. H. W. Verkuijlen, Q. Zhang, J. Kragten, P. J. M. Van Bentum, J. H. Bitter, P. E. de Jongh, The role of Ni in Increasing the Reversibility of the Hydrogen Release From Nanoconfined $\mathrm{LiBH}_{4}$. Faraday Discuss, 151 (2011) $47-58$.

[34] G. L. Xia, Y. B. Tan, X. W. Chen, F. Fang, D. L. Sun, X. G. Li, Z. P. Guo, X. B. Yu, Oxygen-free Layer-by-Layer Assembly of Lithiated Composites on Graphene for Advanced Hydrogen Storage, Adv. Sci. 4 (2016) 1600257.

[35] R. Y. Wu, X. Zhang, Y. F. Liu, L. C. Zhang, J. J. Hu, M. X. Gao, H. G. Pan, A Unique Double-Layered Carbon Nanobowl-Confined Lithium Borohydride for Highly Reversible Hydrogen Storage, Small 16 (2020) 2001963.

[36] Z. Ding, H. Li, L. Shaw, High Reversible Capacity Hydrogen Storage Through Nano-LiBH $4+$ Nano- $\mathrm{MgH}_{2}$ System, Energy Storage Mater. 20 (2019) 24-35.

[37] Z. Ding, H. Li, L. Shaw, New Insights into the Solid-state Hydrogen Storage of Nanostructured LiBH $4-\mathrm{MgH}_{2}$ System, Chem. Eng. J. 385 (2020) 123856.

[38] K. Chłopek, C. Frommen, A. Léon, O. Zabara, M. Fichtner, Synthesis and Properties of Magnesium Tetrahydroborate, $\operatorname{Mg}\left(\mathrm{BH}_{4}\right)_{2}$, J. Mater. Chem. 17 (2007) 3496-3503.

[39] G. L. Xia, Y. B. Tan, X. W. Chen, D. L. Sun, Z. P. Guo, H. K. Liu, L. Z. Ouyang, M. Zhu, X. B. Yu, Monodisperse Magnesium Hydride Nanoparticles Uniformly Self-Assembled on Graphene, Adv. Mater. 27 (2015) 5981-5988.

[40] M. L. Christian, K. F. Aguey-Zinsou Core-Shell Strategy Leading to High Reversible Hydrogen Storage Capacity for $\mathrm{NaBH}_{4}$, ACS Nano 6 (2012) 77397751.

[41] C. X. Hou, J. Wang, W. B. Zhang, J. J. Li, R. H. Zhang, J. J. Zhou, Y. Q. Fan, D. J. Li, F. Dang, J. Q. Liu, Y. Li, K. Liang, B. Kong, Interfacial Superassembly 
of Grape-Like MnO-Ni@C Frameworks for Superior Lithium Storage, ACS Appl. Mater. Interfaces 12 (2020) 13770-13780.

[42] G. L. Xia, Y. B. Tian, X. W. Chen, D. L. Sun, Z. P. Guo, H. K. Liu, L. Z. Ouyang, M. Zhu, X. B. Yu, Monodisperse Magnesium Hydride Nanoparticles Uniformly Self-Assembled on Graphene, Adv. Mater. 27 (2015) 5981-5988.

[43] L. Z. Ouyang, X. S. Yang, M. Zhu, J. W. Liu, H. W. Dong, D. L. Sun, J. Zou, X. D. Yao, Enhanced Hydrogen Storage Kinetics and Stability by Synergistic Effects of in Situ Formed $\mathrm{CeH}_{2.73}$ and $\mathrm{Ni}$ in $\mathrm{CeH}_{2.73}-\mathrm{MgH}_{2}-\mathrm{Ni}$ Nanocomposites, J. Phys. Chem. C 118 (2014) 7808-7820.

[44] P. Mauron, F. Buchter, O. Friedrichs, A. Remhof, M. Bielmann, C. N. Zwicky, A. Züttel, Stability and Reversibility of $\mathrm{LiBH}_{4}$, J. Phys. Chem. B 112 (2008) 906-910.

[45] V. Bérubé, G. Radtke, M. Dresselhaus, G. Chen, Size Effects on the Hydrogen Storage Properties of Nanostructured Metal Hydrides: A Review, Int. J. Energy Res. 31 (2007) 637-663.

[46] A. Remhof, P. Mauron, A. Züttel, J. P. Embs, Z. Łodziana, A. J. RamirezCuesta, P. Ngene, P. E. de Jongh, Hydrogen Dynamics in Nanoconfined Lithiumborohydride, J. Phys. Chem. C 117 (2013) 3789-3798.

[47] O. Friedrichs, A. Remhof, S. J. Hwang, A. Züttel, Role of $\mathrm{Li}_{2} \mathrm{~B}_{12} \mathrm{H}_{12}$ for the Formation and Decomposition of $\mathrm{LiBH}_{4}$, Chem. Mater. 22 (2010) 3265-3268. 


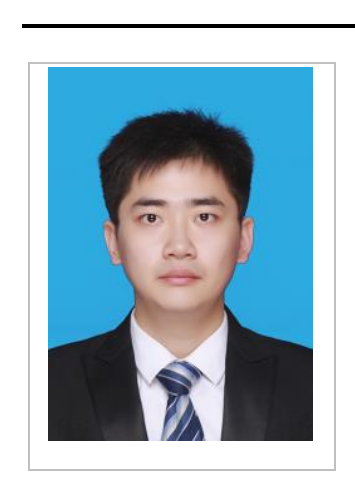

Xin Zhang was born in Henan, China, in 1987. He received his Ph.D. in Materials Science and Engineering from Zhejiang University in 2016. Now, he continues his research in Zhejiang University as a postdoctoral research fellow (working with Prof. Yongfeng Liu). His research is focused on nanostructured materials for solid-state hydrogen storage.

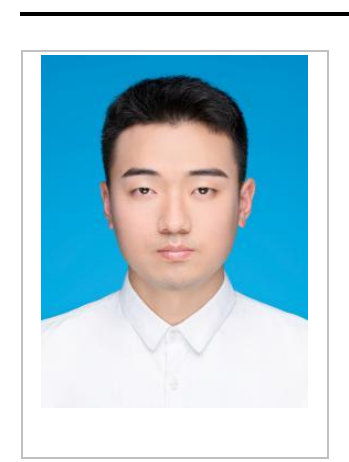

Lingchao Zhang was born in Zhejiang, China, in 1997. He received his B.S. degree in Materials Science and Engineering from Zhejiang University in 2018. After graduation, he started his $\mathrm{Ph} . \mathrm{D}$. study under the supervision of Prof. Yongfeng Liu. His research is focused on solid-state hydrogen storage materials.

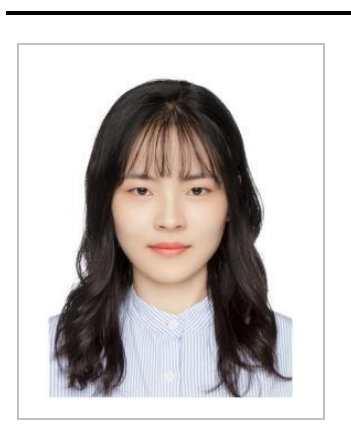

Wenxuan Zhang was born in Hubei, China, in 1996. She received her B.S. degree in School of Materials and Metallurgy from Wuhan University of Science and Technology in 2019. After graduation, she started her Ph.D. study under the supervision of Prof. Yongfeng Liu. Her research is focused on solid-state hydrogen storage materials.

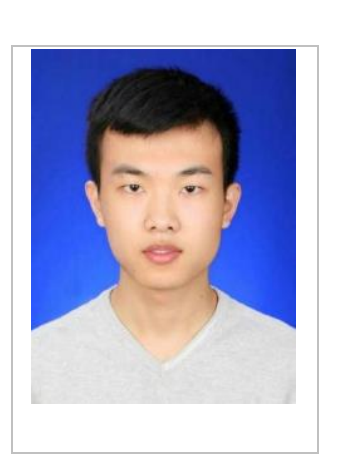

Zhuanghe Ren was born in Shandong, China, in 1994. He received his B.S. degree in Materials Forming and Control Engineering from Xi'an University of Technology in 2016. After graduation, he started his Ph.D. study under the supervision of Prof. Yongfeng Liu at the School of Materials Science and Engineering, Zhejiang University. His research is focused on hydrogen storage materials.

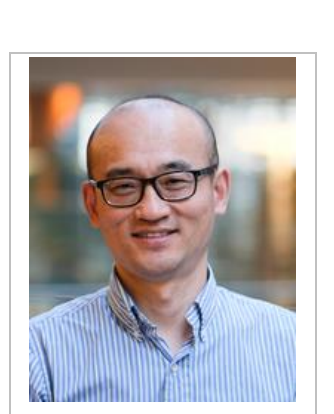

Zhenguo Huang received his Ph.D. from the University of Wollongong, Australia. He was awarded a Discovery Early Career Research Award and Future Fellowships by the Australian Research Council. He is a recipient of the Humboldt Research Fellowship for Experienced Researchers, the Chair of the International Hydrogen Carriers Alliance, and a graduate of Australian Institute of Company Directors. His research is centered on boron chemistry for energy conversion and storage. Research interests are in the fields of hydrogen storage materials, electrolytes, and two-dimensional boron-containing nanosheets. 


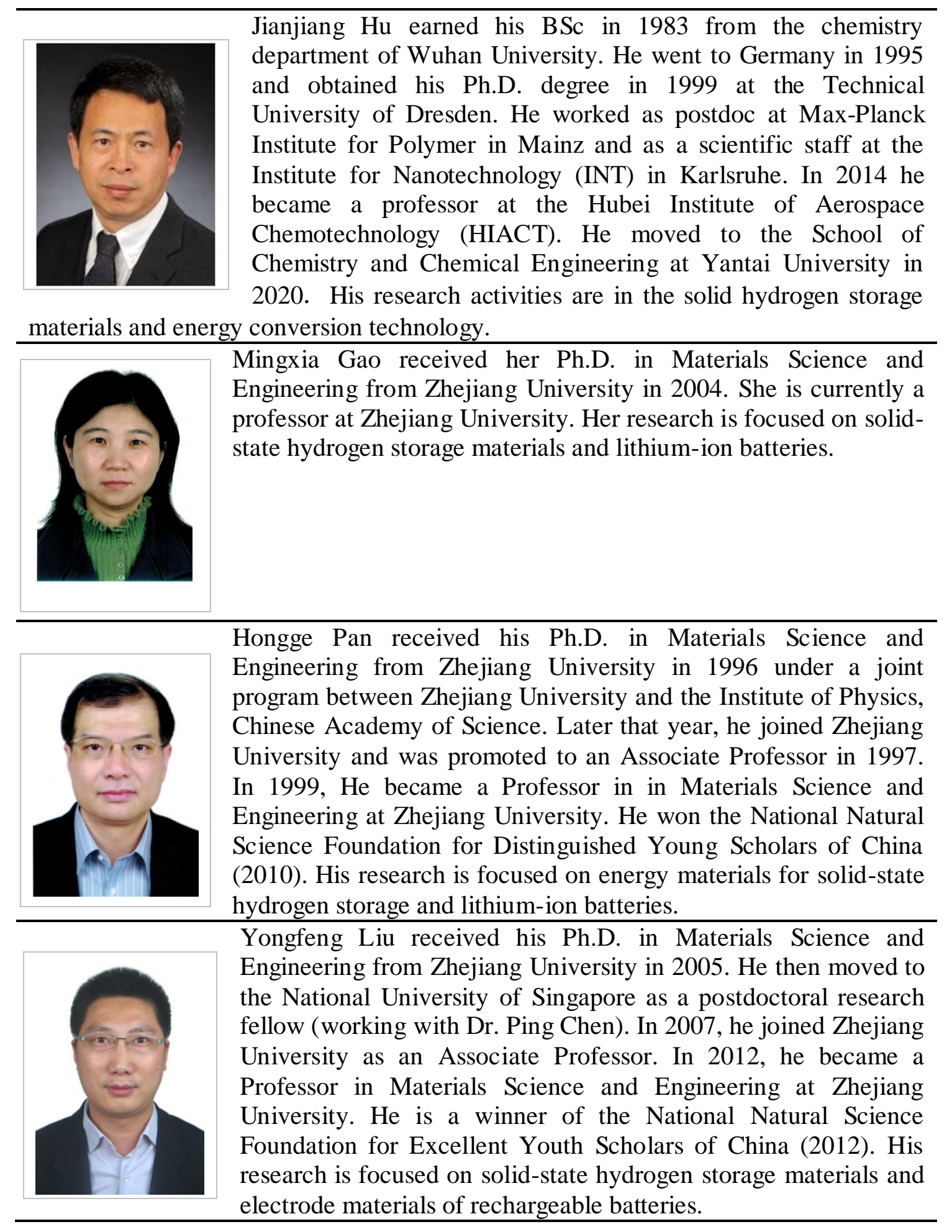

